\title{
Establishment of a Cantharellus cibarius culture collection in Finland
}

\author{
MERJA ITÄVAARA and HARRI WILLBERG
}

During autumn 1987, Cantharellus cibarius strains were isolated at several localities in southern Finland. A total of 39 strains were established, all of them originating from spores. Rhodotorula glutinis (see Fries 1979) or tomato roots (Straatsma et al. 1986) were added to the nutrient media with the spores in order to induce germination. Five nutrient media were used for the isolations.

Spore germination was successful only on the Fries and modified Murashige \& Skoogs media. Tomato roots were found to induce germination more effectively than the yeast cells. Although germination was induced by $R$. glutinis, growth of the hyphae ceased and no further development of the mycelia was observed. In contrast, further development of the mycelia occurred when tomato roots were added to the same media. Germination did not take place without the presence of an inducing factor.

All the isolations from the basidiocarps failed owing to strong bacterial contamination. Several bacteriocides were tested without success. In all cases the contaminating bacteria were identified as Pseudomonas cepacea. It would appear that this species may have a symbiotic role in the basidiocarps of Cantharellus cibarius.

In conclusion, isolation of Cantharellus cibarius was successful from the basidiospores only, and not a single strain was obtained from the basidiocarps.

\section{References}

Fries, N. 1979: Germination of spores of Cantharellus cibarius. - Mycologia 71:216-219.

Straatsma, G., van Griensven, L.J.L.D. \& Bruinsma, J. 1986: Root influence on in vitro growth of hy-

phae of the mycorrhizal mushroom Cantharellus cibarius replaced by carbon dioxide. - Physiol. Plant. 676:521528.

Merja Itävaara \& Harri Willberg, VTT, Technical Research Centre of Finland, Food Research Laboratory, SF-02150, Espoo, Finland 